\title{
A fonoAudiologia na relação entre escolas regulares de ensino FUNDAMENTAL E ESCOLAS DE EDUCAÇÃO ESPECIAL NO PROCESSO DE INCLUSÃ ${ }^{1}$ SPEECH THERAPY IN THE INTERACTION BETWEEN REGULAR PRIMARY SCHOOLS AND SPECIAL EDUCATION SCHOOLS IN THE PROCESS OF INCLUSION
}

\author{
Alice de Souza RAMOS2 \\ Luciana Mendonça ALVES 3
}

RESUM 0: a presente pesquisa teve como objetivo conhecer como ocorre o processo de inclusão de crianças com necessidades especiais no Ensino Fundamental, como acontece a comunicação entre escolas de educação especial e regular, bem como a atuação dos inúmeros profissionais envolvidos, enfocando o papel do fonoaudiólogo. Como metodologia, realizou-se um delineamento descritivo e analítico, por meio de inquérito, aplicados em seis Escolas de Educação Especial e seis Escolas de Ensino Regular da Rede Pública Municipal de Belo H orizonte. Partici param do estudo 6 coordenadores e 42 professores de escola regular, nove coordenadores e 61 professores de escola especial, totalizando 118 sujeitos pesquisados. Os questionários abordaram aspectos relacionados à gestão da escola, à formação docente, ao perfil dos alunos, profissionais atuantes no processo educacional, além de formas de contato entre instituições de serviço de Saúde e Educação. $\mathrm{Na}$ análise dos resultados, dentre outras questões, foi observada grande demanda para serviço fonoaudiológico, ainda pouco presente na área educacional. A comunicação entre os dois tipos de escola não acontece em todas as instituições pesquisadas. A mbas possuem conhecimento restrito da fonoaudiologia, principalmente as escolas regulares. Percebeu-se a falta de investimento para aperfeiçoamento pessoal dos professores, bem como para orientação aos pais acerca do processo de inclusão. Concluímos que o campo da fonoaudiologia no processo de inclusão mostra-se extenso e aberto. Sua atuação na promoção da saúde em âmbito escolar depende diretamente da interdisciplinaridade entre serviços da área da Educação e da Saúde, além da parceria entre fonoaudiólogos, educadores e pais.

PALAVRAS-CHAVE: fonoaudiologia; ensino; docentes; comunicação; educação especial.

\begin{abstract}
A BSTRACT: this research aimed to investigate the inclusion process of children with special needs in Primary Schools, interaction among regular schools and special education centers, as well as the role of the many professionals involved, focusing specifically on the speech therapist. The method used was a descriptive analytical survey; a questionnaire was applied in six Special Education Schools and six Regular Schools of the public school system of the city of Belo Horizonte. Six coordinators and 42 teachers from the regular schools and nine coordinators and 61 teachers from the special education schools took part in thestudy, which involved a total of 118 individuals. The questionnaire covered aspects related to school administration, teacher education, student profile, professionals involved in the educational process, and forms of contact between Health and Education institutions that provide services. Among other issues, the analysis of the results showed a great demand for speech therapy services, which as yet are generally unavailable in the field of education. Interaction between the two types of schools does not occur in all the institutions that were researched. Both types have limited knowledge of Speech Therapy, especially in regular schools. The research revealed a lack of investment in teacher development and in parents' orientation regarding the process of inclusion. We concluded that the field of Speech Therapy is yet to be explored in the process of inclusion. Its contribution for health in the school environment depends directly on the interdisciplinary action of the services provided by the fields of Education and Health, and on cooperation among speech therapists, educators and parents.
\end{abstract}

KEYWORD S: speech therapy; teaching; teachers; interaction; special education.

\footnotetext{
${ }^{1}$ Trabal ho Conclusão de Curso realizado pelo Curso de Fonoaudiologia do Centro Universitário Metodista Izabela Hendrix

${ }^{2}$ Fonoaudióloga, graduada pelo Centro Universitário M etodista Izabela Hendrix - fga.alice@gmail.com

${ }^{3}$ Fonoaudióloga, Doutora em Estudos Lingüísticos pela UFMG, Docente do Centro Universitário Metodista Izabela Hendrix -. lumendonca@terra.com.br
} 


\section{INTRODUÇÃO}

A ação educacional inclusiva visa à transformação de uma sociedade mais justa, val orizand o a integração, indistintamente, detodos os cidadãos, euma partici pação eqüitativa na melhoria das condições devida. Ela envolveum processo com inúmeros impasses e resistências, relacionados a uma prática educacional historicamente segregacionista, geradora de exclusão, que, ao invés de buscar melhorias sociais insistia na discriminação e na exclusão de indivíduos com necessidades especiais (GOMES, 2005).

Ainda segundo Gomes (2005), a inclusão escolar do aluno com necessidades especiais causa mudança na perspectiva educacional, exige novos posicionamentos diante dos processos de ensino e aprendizagem à luz de concepções e práticas mais evoluídas, partindo do princípio fundamental do respeito a toda e qualquer diferença ou característica, com a inclusão em arranjos educacionais regulares, para que todos os alunos possam aprender juntos independentemente das limitações ou dificuldades que apresentem. De acordo com Küster, Húngaro e Castel eins (2001), isto acontece com a val orização do aluno como sujeito ativo, criativo, crítico no ato do conhecimento e atuando como coresponsável, sendo a figura principal do processo ensino-aprendizagem.

As práticas essenciais ao exercício dos direitos humanos, quealteram e modificam a extrema desigual dadee contradições de nossa sociedadesão descritas, no Brasil, na Constituição Federal, na Lei deDiretrizes eBases da Educação Nacional (BRASIL, 1996).

Espera-se que a escola, ao oferecer oportunidades para al unos com necessidades especiais, informe-se e oriente-se com profissionais especializados da Educação e da Saúde sobre as especificidades e instrumentos adequados para que o aluno encontre ali um ambiente adequado e que lhe proporcione o maior e melhor aprendizado possível. Silva e A ranha (2005) enfatizam que o paradigma da construção de sistemas educacionais inclusivos, em desenvolvimento, requer relações interpessoais que sejam eficientemente acolhedoras para todos, ou seja, que atendam às necessidades educacionais de todos, inclusive dos que apresentam necessidades educacionais especiais.

A Constituição Federal (BRASIL, 1988) garante a todos o direito à educação e ao acesso à escola. A lém disso, el ege como um dos princípios para o ensino, a "igual dade de condições de acesso e permanência na escola" (art.206, inc. I), acrescentando que o "dever do Estado com a educação será efetivado mediante a garantia de acesso aos níveis mais elevados do ensino, da pesquisa e da criação artística, segundo a capacidade de cada um" (art.208, V). Toda escola, assim reconhecida pelos órgãos oficiais como tal, deve atender aos princípios constitucionais, não podendo excluir nenhuma pessoa em razão de sua origem, raça, sexo, cor, idade, deficiência ou ausência dela. 
O conceito de inclusão desenvolveu-sena década de 90, com a proposta deeducação para todos, assinada em Jontiem, Tailândia, culminando na Declaração de Salamanca em 1994 (BRASIL, 1994) e no Brasil pela LDB 9394/ 96 (BRASIL, 1988; GOMES, 2005; BUEN O, 2001). A Declaração deSalamanca tem como princípio fundamental que as escolas têm o dever de acolher indistintamente todas as crianças, independentemente de suas condições sociais, culturais, emocionais, físicas ou lingüísticas, sejam elas com deficiência ou bem dotadas.

A LDB 9394/ 96 acrescenta ainda que “haverá, quando necessário, serviços de apoio especializado, na escola regular, para atender às peculiaridades da clientela de educação especial".

Tanto o documento mundial como ambos os documentos nacionais não só reformulam ebuscam qualificar o atendimento educacional oferecido, como prioritariamente salientam e asseguram a promoção do direito à educação, incluindo no âmbito escolar um grupo social, que atéentão era pouco considerado: trata-se de alunos com necessidades especiais. A Secretaria de Educação Especial do M inistério da Educação edo Desporto (1998) propõe as seguintes características referentesàs necessidades especiais dos alunos: superdotação (notável desempenho eel evada potencial idade dos aspectos de capacidade intelectual ); condutas típicas (manifestações de comportamento típicas de portadores de síndromes e quadros psicológicos, neurológicos e psiquiátricos); deficiência auditiva (perda total ou parcial, congênita ou adquirida, da capacidade de compreender a fala por intermédio do ouvido); deficiência física (variedade de condições não sensoriais que afetam o individuo em termos de mobilidade, de coordenação motora geral ou da fala); deficiência mental (funcionamento intelectual geral significativamente abaixo da média); deficiência visual (redução ou perda total da capacidade de ver com o melhor olho após a mel hor correção ótica); deficiência múltipla (associação, no mesmo individuo, de duas ou mais deficiências primárias, mental/ visual/ auditiva/ física).

A ligação entre a Fonoaudiologia e o processo de educação inclusiva pode ser vista no Decreto $\mathrm{N}$ ㅇ‥218, de 31 de maio de 1982, que regulamenta a Lei nำ6.965, de09 de dezembro de 1981. Eledispõe sobrea regulamentação da profissão deFonoaudiólogo edetermina outras providências, como as relacionadas ao campo eatividade profissional, que incluem assessorar órgãos eestabelecimentos públicos, autárquicos, privados ou mistos no campo da Fonoaudiologia, participar da equipe de orientação e planejamento escolar, inserindo aspectos preventivos ligados a assuntos fonoaudiológicos. Estes evidenciam a função efetiva do fonoaudiólogo na área de Educação.

O fonoaudiólogo é capaz de criar condições favoráveis e eficazes para queas capacidades de cada al uno possam ser exploradas ao máximo, não no sentido deeliminar problemas, mas sim baseado na crença de que determi nadas situações eexperiências podem facilitar eincrementar o desenvolvimento ea aprendizagem. Ele preocupa-se com sugestões de técnicas que auxiliem a preparar as crianças 
para alfabetização e para as etapas posteriores a ela, em medidas de caráter profilático (GIROTO, 1999). O fonoaudiólogo atua em consonância com a escola a fim de ser fonte empreendedora na produção do conhecimento e facilitador de vivências em grupo com os alunos e professores, propiciando mediação entre o saber elaborado e o conhecimento a ser produzido (KÜSTER; HÚNGARO; CASTELEINS, 2001; SILVA; ARANHA, 2005; LUZA RDO; NEMR, 2006).

Pacheco e Caraça (1999) delimitam que nas escolas especiais, o planejamento é elaborado de acordo com as dificuldades que as crianças apresentam. Os fonoaudiólogos devem fornecer assistência e suporte para os professores das classes especiais, proporcionando, por meio de orientações e de planejamento direcionados às dificuldades específicas de cada patol ogia atendida por estas classes, melhores condições para que as crianças que forem integradas tenham possibilidades de acompanhar as atividades propostas nas classes comuns (GIROTO, 1999).

De acordo com Silva e Aranha (2005), no processo de construção de uma classe inclusiva, as relações entre professor e al uno surgem como elemento de fundamental importância, já que é no contexto das relações que o respeito e a atenção pedagógica flexível e individualizada vão se efetivar. Compreendendo os docentes como sujeitos que podem construir conhecimento sobre o ensinar em sua atividade, na dimensão coletiva e contextual izada institucional ehistoricamentee a fim de possi bilitar a reflexão crítica sobre as suas próprias práticas, sua condição de trabal hador, bem como os limites e possibilidades do seu trabal ho, o serviço de Fonoaudiologia oferece sua parceria (PIMENTA, 2005).

Esteartigo abre perspectiva para um maior conhecimento do modo de atuação da Fonoaudiologia no processo de inclusão, visando uma prática mais integral e eficiente. Além disso, por ser uma prática relativamente recente, a literatura referente a esse assunto mostra-se escassa, e esse tipo de estudo pode facilitar o desenvolvimento de pesquisas na área e realização de outros trabal hos, viabilizando maior entendimento da complexidade acerca da inclusão eda inserção do fonoaudiólogo nesse processo.

Buscando conhecer como ocorre o processo de inclusão de crianças com necessidades especiais no Ensino Fundamental da Rede Pública Municipal de Belo Horizonte, algumas mudanças e adaptações que são feitas na instituição escolar em função destas crianças e a comunicação entre escolas de educação especial e regular, esta pesquisa visa estudar aspectos que interferem na educação inclusiva, bem como a atuação dos inúmeros profissionais envolvidos, enfocando o papel da Fonoaudiologia.

\section{Material e métodos}

O presente estudo segue o delineamento do tipo observacional descritivo e analítico, por meio de inquérito. O Comitê de Ética em Pesquisa do 
Instituto M etodista Izabela Hendrix aprovou esta pesquisa sob protocolo denúmero 036/ 2006.

Foram elaborados questionários com perguntas objetivas e aplicados em seis Escolas de Educação Especial e seis Escolas de Ensino Regular da Rede Pública Municipal de Belo Horizonte. Os nomes das Escolas Municipais foram consultados no Núcleo de Inclusão da SMED (Secretaria Municipal de Educação) da Prefeitura de Belo Horizonte. As instituições foram indicadas pelo número significativo de crianças com necessidades especiais. Já as outras escolas incluem nomes que possuem convênio deestágio com o curso deFonoaudiologia do Centro Universitário Metodista Izabela Hendrix; as demais foram indicadas por profissionais da área de Saúde e Educação. A pós contato telefônico, as citadas escolas aceitaram a realização da pesquisa. Houvetambém autorização por escrito, por meio de cartas de autorização direcionadas às escolas e uso do Termo de Consentimento Livre e Esclarecido para cada voluntário.

Os questionários foram direcionados para a coordenação da escola e seus respectivos professores, que atuam com crianças de seis a 14 anos de idade (Ensino Fundamental). O número de coordenadores de escola regular foi seis eo de professores 42 . O de coordenadores de escola especial foi novee de professores 61 , totalizando 118 sujeitos pesquisados.

Houve um questionário específico para coordenadores e outro para professores, assim como houve diferenças entre os questionários direcionados às escolas de educação especial e escolas de ensino regular, totalizando quatro questionários. Cada questionário possui aproximadamente 18 perguntas objetivas, tendo, em comum, questões que abordaram aspectos relacionados à gestão da escola, à formação docente, ao perfil dosal unos, profissionais atuantes no processo educacional, além de formas de contato entre instituições de serviço de Saúde e Educação.

As perguntas incluem: a) os tipos de necessidades especiais que os alunos possuem; b) existência de crianças com necessidades especiais que estudem em dois tipos de escola (regular e especial ); c) a opinião do entrevistado sobre essa situação; d) presença de atendimento terapêutico; e) tipo de atendimento; f) existência de lugar ou profissionais específicos para encaminhamento de alunos; g) os profissionais que trabal ham na escola; h) planos para contratação de al gum outro profissional; i) percepção sobre função do fonoaudiólogo; j) meios de instrumental ização quanto à inclusão escolar para funcionários e pais dos alunos; e k) percepção que a escola encontra-se atualmente em relação ao processo de inclusão.

Especificamente para os professores de escola regular, perguntou-se sepercebem necessidade deacompanhamento terapêutico extra-escolar para alunos que foram incluídos e de qual tipo e também sobre o desempenho escolar desses alunos, considerando a aprendizagem, em comparação com os outros alunos. Para a coordenação da escola regular questionou-se como é a adaptação desses novos 
alunos, motivo de evasão (quando houver) e se há comunicação entre a escola pesquisada e al guma outra de educação especial.

Para a coordenação da escola especial, questionou-se sobre encaminhamento para escola regular equem atua nessa decisão, o motivo deretorno do aluno (se houver) para escola especial, deixando de freqüentar escola regular. Para os professores de educação especial, se tem contato com os profissionais que atendem o aluno.

Na comparação das respostas dos coordenadores de escolas regulares e especiais e na comparação de resultados dos professores de escolas regulares e especiais, avaliou-se se o tipo de escola (especial ou regular) está associado com as respostas dadas pel os coordenadores. Ou seja, verificar sea proporção deindivíduos em cada categoria de resposta varia significativamente de acordo com o tipo de escola.

Para isso, foi utilizado o teste Qui-quadrado de associação entre duas variáveis categóricas. Como a amostra de coordenadores é pequena, utilizou-se o TesteExato deFisher, queéuma modificação do Qui-Quadrado, também utilizado na análise dos professores, apesar das amostras serem relativamentegrandes, pois há categorias de respostas com freqüências pequenas.

Uma comparação entreos quatro grupos de indivíduos (coordenadores e professores, escolas regulares e especiais) foi feita com relação a uma mesma questão, acerca do que o indivíduo considera ser a função do fonoaudiólogo. 0 teste exato de Fisher foi usado para comparar a proporção de indivíduos que selecionaram ou não uma determinada opção dentro dos quatro tipos de questionários. Um valor p menor que 0,05 indica que há uma diferença significativa entre os percentuais de indivíduos que selecionaram a opção em cada um dos quatro grupos.

A avaliação dos resultados foi feita de forma quantitativa, qualitativa e comparativa, abordando assuntos individuais de cada escola, bem como suas inter-relações.

\section{RESULTADOS}

\subsection{ADOS OBTIDOS DOS COORDENADORES}

Os resultados consistiram na descrição da porcentagem de respostas obtidas por cada grupo pesquisado e al gumas correlações entre os grupos. Em relação ao tipo de necessidades especiais existentes nas escolas (Gráfico 1), observou-se maior resposta em síndromes/ casos psicológicos, neurológicos e psiquiátricos em ambos os tipos de escolas, sendo $100 \%$ nas especiais e $83,3 \%$ nas regulares. Em segundo lugar, na escola regular, a deficiência física foi citada (66,7\%) e na escola especial, a deficiência mental (88,9\%). 


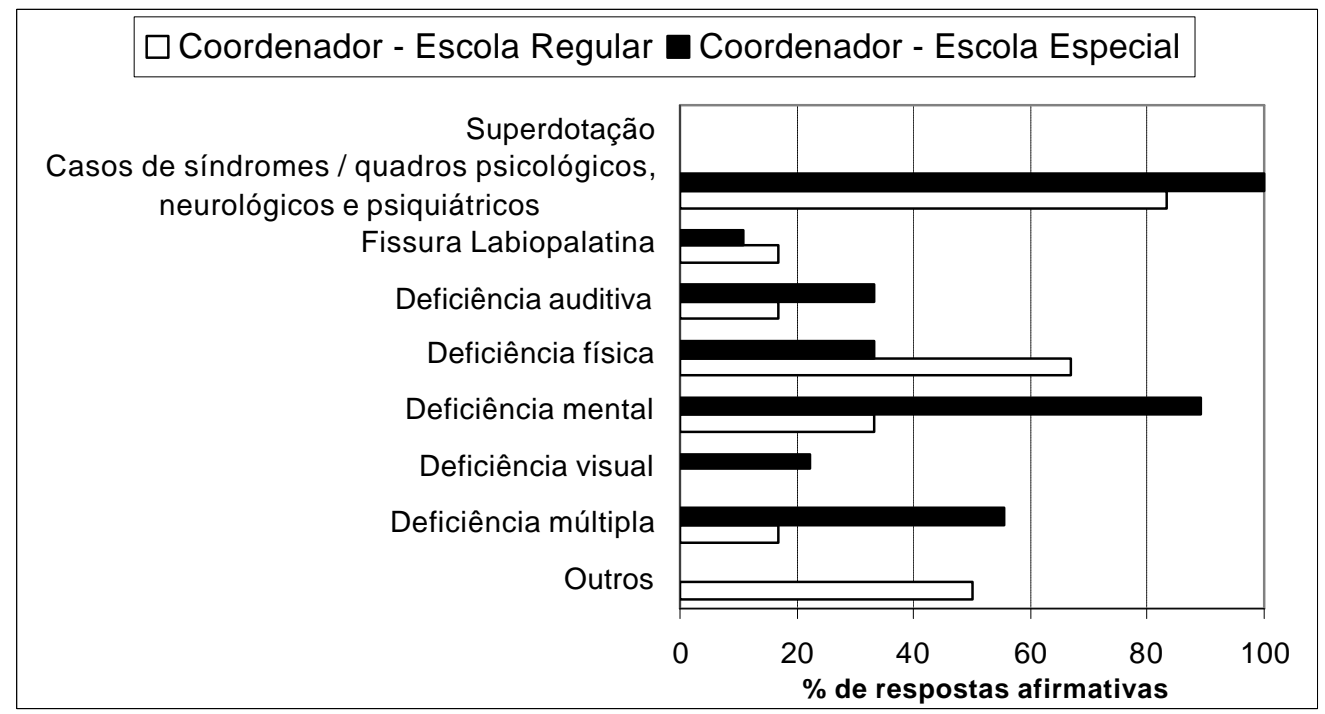

Gráfico 1 - Comparação das respostas dos coordenadores de escolas regulares e especiais quanto às necessidades especiais encontradas nas escolas

Diantedeum processo de transferência dealunos, a comunicação entre escolas ocorreem $50 \%$ das vezes em escola regular e em escola especial, $77,8 \%$. Os motivos de evasão da escola regular citados foram: mudança para outra escola regular e mudança de endereço.

Quando fazem encaminhamento para serviço deFonoaudiologia, 50\% dos coordenadores de escol as regulares têm profissionais específicos para indicar enas escolas especiais $77,8 \%$. Os atendimentos complementares/ terapêuticos fora da escola regular, de acordo com os coordenadores, são feitos por fonoaudiólogos (83,3\%), seguido de psicólogos, fisioterapeutas e terapeutas ocupacionais (66,7\%), os três com a mesma porcentagem. Não há planos para contratação de nenhum outro profissional.

$\mathrm{N}$ as escolas especiais há atendimento, principalmente, de Fonoaudiologia e Psicologia (44,4\%), e fora da escola, de Terapia Ocupacional $(77,8 \%)$, seguidos de Fonoaudiologia ePsicologia $(66,7 \%)$. Quem atua na mudança da criança para a escola regular são os pais (100\%), o professor (100\%), o coordenador $(88,9)$, seguidos do pedagogo $(77,8 \%)$, além de profissionais da área da saúde.

Em 66,7\% das escola regulares a inclusão escolar não foi abordada formalmente como instrumentalização para os funcionários. Já em todas as escolas especiais este assunto é discutido em reuniões ordinárias. Outras formas de 
aprimoramento quanto à inclusão escolar foram citadas pel os coordenadores, como cursos e palestras.

Os pais dos alunos receberam, nas escolas especiais (100\%) e escolas regulares (33,3\%) orientação em reuniões. Em 66,7\% das escolas regulares, o assunto inclusão escolar não foi abordado formalmente.

Em relação ao processo de inclusão, todos os coordenadores deescolas regulares consideram que possuem profissionais sem qualificação adequada e também que o contato e a assistência com instituições de ensino especializado é insuficiente. $22,2 \%$ dos coordenadores das escol as especiais julgam que possuem profissionais insuficientemente qualificados. 33,3\% dos coordenadores de escolas especiais e dos coordenadores de escolas regulares destacaram que, em relação à acessibilidade, a estrutura física éinadequada.

\subsection{DADOS OBTIDOS DOS PROFESSORES}

Quanto à participação em al gum tipo de capacitação, com o processo de educação inclusiva, os professores de escolas regulares citaram: orientação/ conversa informal com serviço pedagógico (40,5\%) e cursos/ palestras oferecidos pela escola (28,6\%). Os de escola especial: cursos/ palestras oferecidos pela escola (78,7\%) e orientação/ conversa informal com serviço pedagógico (52,5\%). Cursos/ palestras particulares, financiados por conta própria (45,9\% professores de escolas especiais, $21,4 \%$ nos outros) e orientação/ conversa informal com fonoaudiólogo aconteceram menos (26,2\% dos professores de escolas especiais, $7,1 \%$ nos outros).

Para professores de escolas especiais, as alterações mais encontradas nas crianças com necessidades especiais são: dificuldades deaprendizagem (96,7\%), alterações do desenvolvimento motor $(86,7 \%)$ e alterações cognitivas (85\%), alterações de linguagem $(81,7 \%)$ e alterações de fala (80\%). Para professores de escolas regulares: dificuldades de aprendizagem (83,3\%), alterações delinguagem (78,6\%), al terações do desenvolvimento motor (66,7\%), alterações cognitivas $(61,9 \%)$ e alterações de fala (59,5\%).

A mbos os grupos de professores percebem necessidade de acompanhamento terapêutico extra-escolar, $100 \%$ dos professores de escolas especiais e $97,6 \%$ dos professores de escolas regulares. Os tipos de atendimento são: Fonoaudiologia ( $100 \%$ para os professores de escolas especiais e $90,2 \%$ para os professores de escolas regulares), seguido de Psicologia e Terapia Ocupacional (Gráfico 2). 56,6\% dos professores de escolas especiais e 54,3\% dos professores de escolas regulares não conhecem os profissionais (psicólogo, fonoaudiólogo, fisioterapeuta, dentre outros) que atendem o aluno. 


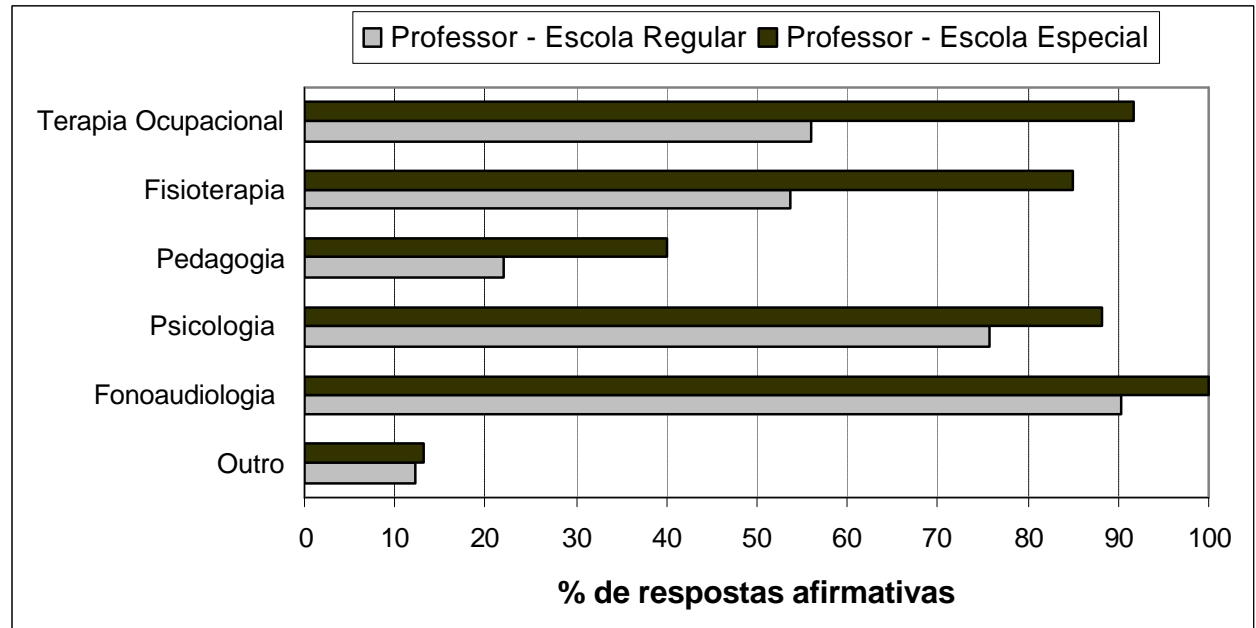

Gráfico 2 - Comparação das respostas dos professores de escolas regulares e especiais quanto aos tipos de acompanhamento terapêutico extra-escolar que percebem necessidade para os alunos com de necessidades especiais.

Quando fazem encaminhamento para serviço fonoaudiológico, 75\% dos professores de escolas especiais e $28 \%$ dos professores de escolas regulares têm profissionais específicos para indicar, com uma diferença significativa $(p=0,000)$ entre os grupos. Quando questionados sobre a necessidade da inserção de outros profissionais na equipe escolar, $97,1 \%$ dos professores de escolas regulares e $83,7 \%$ dos professores de escolas especiais optaram pel o fonoaudiólogo. Possivelmente, alguns dos profissionais que foram menos citados podem já fazer parte da equipe escolar (Gráfico 3).

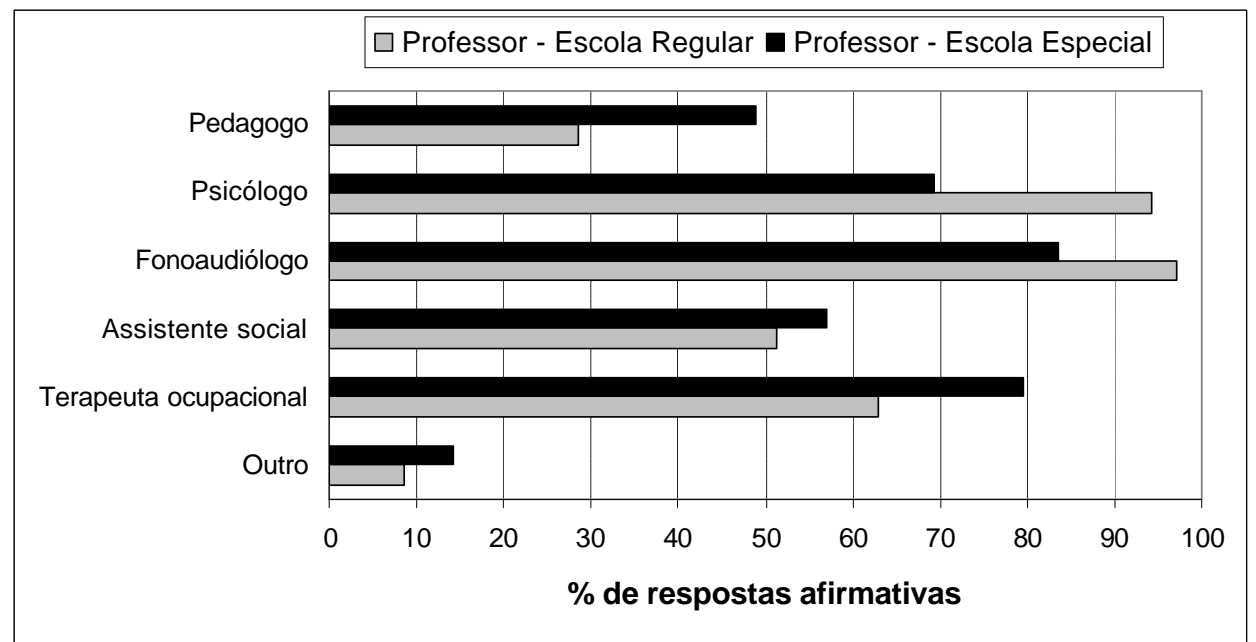

Gráfico 3- Comparação das respostas dos professores deescolas regulares eespeciais quanto à necessidade da inserção de determinados profissionais na equipe escolar. 
De acordo com 52,6\% dos professores de escolas regulares, o desempenho escolar dos alunos com necessidades especiais, considerando a aprendizagem, em comparação com os outros alunos é ruim. Quanto à intenção comunicativa e socialização, para $44,7 \%$ é satisfatória e para o mesmo número $(44,7 \%)$ é regular. Quanto à fala, 71,8\%, considerou regular. Quanto à linguagem (compreensão e expressão de idéias), 69,2\% classificaram como regular equanto à leitura e escrita, $63,4 \%$ dos professores de escolas regulares acham ruim.

\subsection{COMPARAÇão ENTRE OS DADOS OBTIDOS DE PROFESSORES E COORDENADORES SOBRE A FUNÇÃO DO FONOAUDIÓLOGO}

Houve uma pergunta em comum em todos os questionários relacionada à atuação fonoaudiológica. As respostas são demonstradas a seguir no gráfico 4.

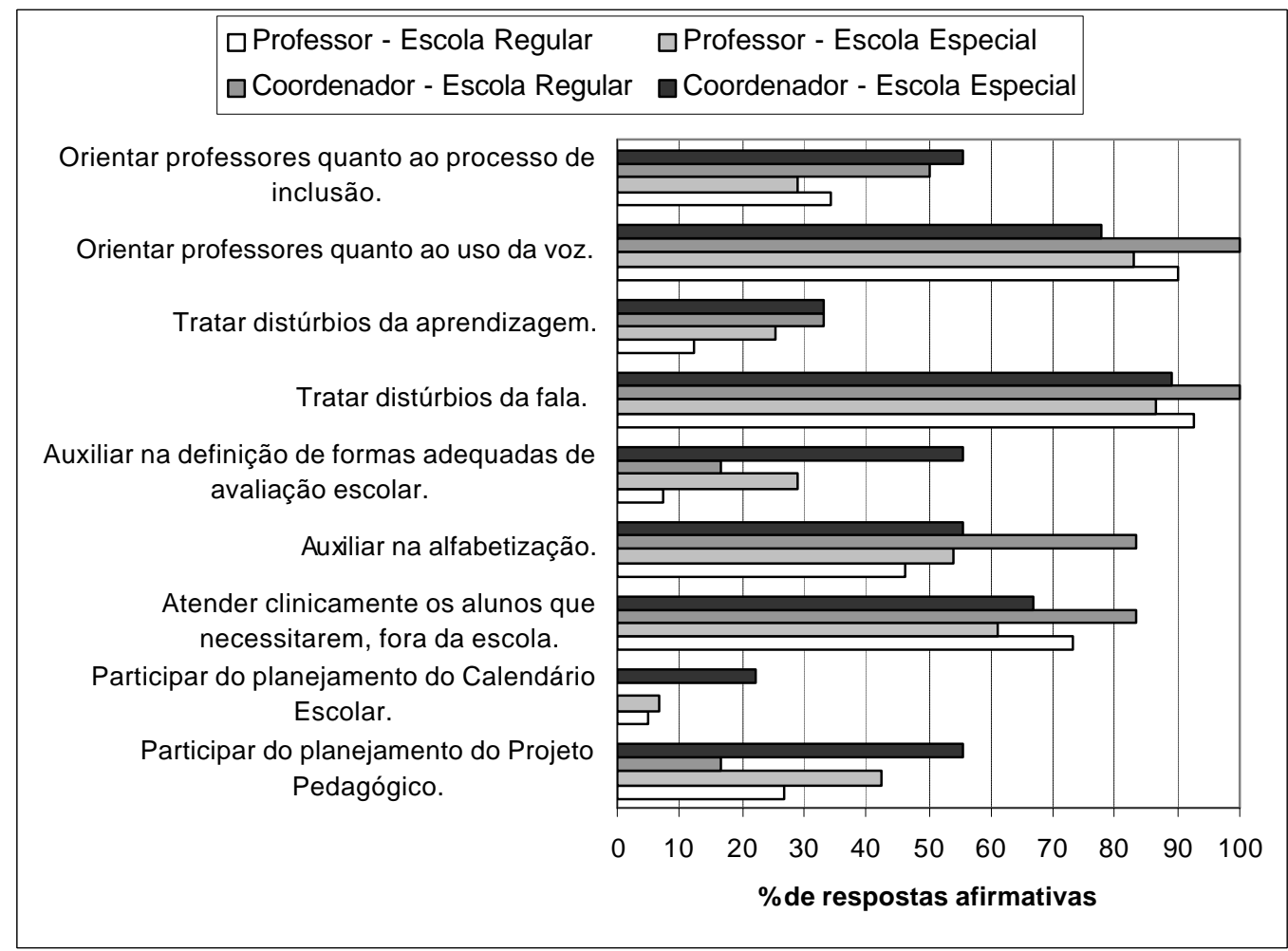

Gráfico 4 - Comparação das respostas dos coordenadores de escolas regulares e especiais quanto ao que consideram ser função do fonoaudiólogo.

As funções do fonoaudiólogo mais citadas foram: tratar distúrbios da fala ( $P R=92,7 \%$; $P E=86,4 \% ; C R=100 \% ; C E=88,9 \%$ ), orientar professores quanto ao 
uso da voz ( $P R=90,2 \% ; P E=83,1 \% ; C R=100 \% ; C E=77,8 \%$ ), atender clinicamente os alunos quenecessitarem, fora da escola ( $P R=73,2 \% ; P E=61 \% ; C R=83,3 \% ; C E=66,7 \%$ ) e auxiliar na alfabetização ( $P R=46,3 \% ; P E=54,2 \% ; C R=83,3 \% ; C E=55,6 \%$ ).

Participar do planejamento do projeto pedagógico e do calendário escolar foram funções mencionadas em maior número pelos professores e coordenadores das escolas especiais. Projeto pedagógico: $C R=16,7 \%$; $P R=26,8 \%$; $\mathrm{CE}=55,6 \% ; \mathrm{PE}=42,4 \%$. Calendário escolar: $\mathrm{CR}=0 \% ; \mathrm{PR}=4,9 \% ; \mathrm{CE}=22,2 \% ; \mathrm{PE}=6,8 \%$.

Foi observada uma diferença significativa $(p=0,004)$ entre o percentual de indivíduos que considera ou não ser função do fonoaudiólogo "Auxiliar na definição de formas adequadas de aval iação escolar". Pode-se observar que esse percentual tende a ser maior entre os indivíduos (professores ou coordenadores) de escolas especiais que entre os de escolas regulares $(C R=16,7 \% ; P R=7,3 \%$; $\mathrm{CE}=55,6 \% ; \mathrm{PE}=28,8 \%$ ).

\section{Dıscussão}

Os resultados indicam que existe demanda significativa para a atuação fonoaudiológica nas escolas regulares e também de ensino especial. Parte dela foi demonstrada pelas alterações e dificuldades encontradas nos alunos com necessidades especiais, que incluem síndrome, deficiência mental, auditiva e múltipla. Ou seja, em todos os quadros apontados, as crianças apresentam alterações comunicativas e de aprendizagem que demandam atuação e orientação fonoaudiológica. No entanto, ressaltamos que, independente da demanda relacionada aos quadros patológicos, a atuação fonoaudiológica se dá no sentido de potencializar o desenvolvimento da comunicação e também de prevenir possíveis distúrbios da comunicação humana. Assim, conforme César e Calheta (2005) apontam, o apoio fonoaudiológico se dá para potencializar as capacidades dos al unos para mel hores resultados pedagógicos einteracionistas com professores e colegas, instaurando a relevância da noção de promoção da saúde no contexto escolar. É importante ressaltar que esta noção de potencial ização das habilidades comunicativas éextensiva a todos os al unos, sejam el es portadores denecessidades especiais ou não. O fonoaudiólogo poderá, inclusive, além dos alunos, abranger todo o pessoal envolvido na educação em suas ações.

Observou-sea necessidade da presença de diversos atores no contexto escolar, tais como coordenadores, professores e terapeutas e da ligação entre eles para o trabalho conjunto no processo de inclusão escolar. A interlocução e a cooperação entreprofessores, fonoaudiólogo edemais profissionais da escola busca reflexão, integração e construção de conhecimentos (CÉSAR; CALHETA, 2005; CRISTOFOLINI; MA GN I, 2002). Na pesquisa realizada, percebeu-sea concordância da necessidade de atendimento complementar e terapêutico aos alunos nas respostas dos professores, tanto de escola regular quanto de especial. 
Para melhor adaptação do aluno eda escola, diante de um processo de transferência de al unos é importante a comunicação entre as escolas, hábito ainda não realizado em todas as escolas pesquisadas. A comunicação permite troca de informações e conhecimentos acerca do aluno, bem como esclarecimento de dúvidas e apoio nas inseguranças. O hábito da comunicação entre as escolas intensifica o vínculo entre as instituições e consolida a inclusão de forma mais organizada. $O$ PR pode ficar mel hor orientado quando sabe sobre a vivência anterior do aluno e sua relação com a escola em queera matriculado.Valeressal tar quea família também deve participar deste eixo, explicando a realidade do aluno e sendo amparada pela nova escola. A final, a formação básica do aluno éfunção do Estado eda família e a mesma deve ser inserida no processo educacional vigente (DIAS et al., 1999).

Possuir serviços clínicos específicos da Fonoaudiologia para indicar (preservando sempre a liberdade de escolha do pai, do profissional de sua preferência) agiliza o acesso e início do contato do aluno com o profissional que necessita. É importante que a escola possua uma relação de troca interdisciplinar com a Fonoaudiologia, o que depende da iniciativa da coordenação da escola e também dos próprios fonoaudiólogos, demonstrando sua qualificação e disponi bilidade para a área educacional. E no caso de já atenderem al gum aluno que foi incluído na rede regular de ensino, buscar presenciar sua vida social e escolar, sem limitar-se ao atendimento clínico. Esta interlocução (Fonoaudiologia - escola - pais - aluno) deve ser uma constante na prática inclusiva clínica e educacional. Sem uma ad equada comuni cação entre todas as partes envol vidas na educação e saúde destes escolares, toda ação se torna isolada, e pequenas ações local izadas não são tão eficazes quanto uma boa e fundamentada ação conjunta.

Percebeu-se a fal ta de investimento para aperfeiçoamento pessoal dos professores para trabalhar com os diferentes, com o novo. É importante que conheçam o desenvolvimento da criança com deficiência, considerando que a competência dos alunos não está restrita às aparências, conhecendo a forma do aluno comunicar e realizar atividades, potencializando a forma singular de comunicação e participação de cada aluno, não vendo a diferença pela ótica da falta, oferecendo desafios compatíveis com a capacidade e possibilidades do al uno epromovendo acessibilidadeao conteúdo. O fonoaudiólogo podeatuar ativamente nessa qual ificação, na promoção depal estras, w orkshops e participações em reuniões, por exemplo. O mesmo mostra-seausente, não fazendo parteda equipe profissional das escolas regulares pesquisadas, mas trabal ha em $44,4 \%$ das escolas especiais. A ausência de fonoaudiólogos nas escolas pode justificar a falta de conhecimento dos professores sobre as ações fonoaudiológicas no âmbito educacional, além de demonstrar assistematici dade da atuação, desfavorecend o o trabal ho progressivo, integrado e eficaz da profissão (BRA SI L; CHIARI, 2006). O trabalho de orientação sobre educação inclusiva deve ser feito também para os pais de todos os alunos, podendo enfocar a democratização das oportunidades educacionais, o processo desocialização entre os al unos, além das múltiplas formas delinguagem. Destacase, portanto, a necessidade de um maior investimento em educação continuada 
para toda a equipe envolvida no processo de inclusão, possibilitando um bom embasamento teórico, além de trocas de experiências e vivências práticas, sempre sob um olhar multidisciplinar.

As escolas especiais pesquisadas mostraram-se mais preparadas tecnicamente, além de possuir maior amparo e relação mais próxima com profissionais da área da Saúde, como fonoaudiólogos, psicólogos e terapeutas ocupacionais, que fazem parte da equipe escolar em algumas instituições, atendendo alunos e dando suporte ao professor. Portanto, há a necessidade de aprimoramento do serviço nas escolas regulares para melhor adaptação do aluno com necessidades educativas especiais, o que não isenta as escolas especiais de buscarem constante qual i dad ee aperfeiçoamento do serviço, bem como ampliação do serviço de Fonoaudiologia nas respectivas instituições educacionais.

Para a mai oria dos professores de ensino regular, o desempenho dos alunos com necessidades especiais, em comparação com os outros, em relação à aprendizagem, à leitura eà escrita éruim. Mais uma vez, vê-se a possibilidade de uma intervenção fonoaudiológica positiva, que desenvolveria ações deestimulação da aprendizagem e aprimoramento de leitura e escrita com todos os alunos, tendo o benefício de atividades em grupo, que propiciem, além de atividades cognitivas diretamente relacionadas à leitura e escrita, habilidades auditivas, de consciência fonológica, figura-fundo auditiva evisual, entre outras habilidades. Uma pesquisa feita por Brasil e Chiari (2006) demonstrou que um treinamento realizado com aplicação de questionários e um software específico com professores do Ensino Fundamental foi efetivo para conscientizar sobre atuação da Fonoaudiologia na escola, alertar e oferecer subsídios para a compreensão da importância para a estimulação das habilidades de leitura e escrita, a identificação da criança com distúrbio e seu encaminhamento para o fonoaudiólogo. A eficácia da instrumentalização fonoaudiológica referenteà linguagem, fala ecomunicação para professores da Educação Infantil, por meio da distribuição de periódicos mensais eformulários para comparação de dados, também foi pesquisada e publicada por Luzardo e Nemr em 2006.

As primeiras intervenções fonoaudiológicas na escola tinham caráter predominantementearraigado no ideal decura esupressão de problema, voltadas para questões norteadas pelo processo patológico (KÜSTER; HÚNGARO; CASTELEINS, 2001; CÉSAR; CALHETA, 2005; CRISTOFOLINI; MAGNI, 2002; BRA SI L; CHIA RI , 2006; VA LENTE et al., 2006). Infelizmente, as respostas obtidas pel os questionários dos professores e coordenadores foram semel hantes eindicam a permanência desta percepção sobre a área de atuação fonoaudiológica. O conhecimento sobre a atuação desse profissional mostrou-se com considerável restrição e, prioritariamente, clínico, principalmente nas escolas regulares. Entretanto, as possibilidades de atuação do fonoaudiólogo são idealmente bem mais amplas. Funções como participação no planejamento do projeto pedagógico edo cal endário escolar eorientação para professores quanto ao processo deinclusão 
foram pouco citados pelos professores e coordenadores pesquisados. Um planejamento pedagógico bem elaborado, e com contribuições multidisciplinares, possi bilita uma maior ativação da inteligência dos alunos, auxilia na evolução do pensamento e de todas as funções mentais superiores (ARANEGA; NASSIM; CHIAPPETTA, 2006).

O item relacionado à abordagem com distúrbios de aprendizagem foi pouco mencionado também, demonstrando quea população pesquisada não atribui a função de lidar com esses transtornos à Fonoaudiologia. No entanto, o fonoaudiólogo é habilitado a diagnosticar, tratar e prevenir os transtornos de aprendizagem da leitura e escrita, assim como traçar estratégias, junto à equipe pedagógica, para estimular preventivamente estas habilidades.

A Resolução CFFa no 309 de 01/ 04/ 2005 dispõe sobre a atuação do fonoaudiól ogo no ensino fundamental, educação especial, dentre outros tipos de instituições. Nas escolas regulares, cabe ao profissional desenvolver ações que favoreçam eotimizem o processo deensino eaprendizagem por meio de assessoria, orientações, triagens, programas específicos eações em parceria com os educadores. É vedado ao fonoaudiólogo realizar atendimento clínico/ terapêutico dentro dessas instituições. Já nas escolas de educação especial, além das ações de promoção da saúde e prevenção de alterações relacionadas à audição, linguagem, motricidade orofacial e voz, o atendimento cínico poderá ocorrer quando necessário desde que não interfira no horário das atividades escolares.

Esclareço que, devido aos extensos questionários e a diversidade dos assuntos relacionados, não foi possível abordar todos os achados. No entanto, os aspectos mais rel evantes foram abordados nesteartigo. Futuras publicações poderão trazer maior abrangência ao estudo.

Assim, o campo de trabalho para Fonoaudiologia no processo de inclusão escolar mostra-se extenso e aberto. Isso depende de uma conduta mais próxima entre a área de Educação e a área da Saúde, ambas visando a promoção da qualidade de vida bio-psico-social dos alunos.

\section{CONCLUSÃo}

O presente estudo buscou evidenciar a contribuição da Fonoaudiologia no processo de ensino-aprendizagem e na construção de sistemas educacionais inclusivos.

A atuação na promoção da saúde em âmbito escolar depende diretamentedainterdisciplinaridadeentre serviços da área da Educação e da Saúde, além da parceria entre fonoaudiólogos, educadores e pais.

Enfatiza-se também a importância de pesquisas no campo, visando aperfeiçoamento continuado na formação de docentes e discentes. 


\section{REFERÊNCIAS}

ARANEGA , C. D. T.; NASSIM , C. P.; CHIA PPETTA A. L. M. A importância do brincar na educação infantil. Revista Cefac, São Paulo, v. 8, n. 2, p. 141-6, 2006.

BRASIL, C. C. P.; CHIA RI, B. M. Integrando fonoaudiologia e escola: uma proposta para prevenção do distúrbio de leitura e escrita. Fono A tual, São Paulo, v. 36, p. 35-43, 2006.

BRASIL. Constituição (1988). Constituição da República Federativa do Brasil, 1988. Brasília: Senado Federal, Centro Gráfico, 1988.

BRASIL. Lei F ederal № 9.394, de 20 de dezembro de 1996. Dispõe sobreas Diretrizes eBases da Educação N acional. Diário Oficial da União, Brasília, 23 dez.1996.

BRA SIL, Ministério da Educação e do Desporto. A daptações curriculares, estratégias para a educação de alunos com necessidades especiais: parâmetros curriculares nacionais. Secretaria de Educação Especial - Brasília, 1998.

BRASI L. D eclaração de Salamanca elinha de ação sobre as necessidades educativas especiais. Brasília, Coordenadoria Nacional para Integração da Pessoa Portadora de Deficiência (CORDE), 1994.

BUENO, J. G. S. A inclusão escolar de alunos deficientes em classes comuns do ensino regular. Temas sobre D esenvolvimento, São Paulo, v. 9, n. 54, p. 21-27, 2001.

CÉSAR, C. P. H. R.; CALHETA, P. P. A ssessoria eFonoaudiologia - perspectivas de ação. Rio de Janeiro: Livraria eEditora Revinter Ltda, 2005.

CONSELHO FEDERAL DE FON OAUDIOLOGIA. Lè n. 6.965, de 09 dedezembro de 1981. Dispõe sobre a regulamentação da profissão de Fonoaudiólogo, e determina outras providências. Brasília, 9 dez. 1981.

CON SELHO FEDERA L DE FONOAUDIOLOGIA. R esolução CFFa n 309, de 01 deabril de 2005. Dispõe sobrea atuação do Fonoaudiólogo na educação infantil, ensino fundamental, médio, especial esuperior, e dá outras providências. Brasília, 1 abr. 2005.

CRISTOFOLINI, C.; MA GNI, C. Audição: relatos eexperiências de professores de Ensino Fundamental. Revista Fonoaudiologia Brasil, Brasília, v. 2, n. 2, p. 31-38, 2002.

Decreto No 87.218, de 31 de maio de 1982. Disponível em: <http:/ / www.fonoaudiologia.org.br/ doc/ lei_decreto/ decreto87218.htm> A cesso em: 10 abr. 2006. DIAS, T. R. S. et al. A Surdez na Dinâmica Familiar: estudo de uma população específica. Revista Espaço, Rio de Janeiro, n.11, p. 29-36, 1999.

GIROTO, C. R. M. (Org.). Perspectivas atuais da F onoaudiologia na escola. São Paulo: Plexus Editora, 1999.

GOMES, C. N ecessidades educacionais especiais: concordância de professores quanto à inclusão escolar. Temas sobre D esenvolvimento, São Paulo, v. 14, n. 79, p. 23-31, 2005.

KÜSTER, A. M. B.; HUN GARO, R. O.; CASTELEINS, V. L. A fonoaudiologia educacional ea escola: muito a fazer, muito a pensar, muito a estudar.J ornal Brasileiro deF on oaudiologia, Curitiba, v. 3, n. 9, p. 332-338, 2001.

LUZARDO, R.; NEMR, K. Instrumental ização fonoaudiológica para professores da educação infantil. Revista CEFA C, São Paulo, v. 8, n. 3, p. 289-300, 2006.

PACHECO, E. C. F. C. P.; CARA ÇA, E. B. Fonoaudiologia Escolar. In: Ferreira, LP. et al. Temas de Fonoaudiologia. 8. ed. São Paulo: Edições Loyola; 1999. 
PIMENTA, S.G. Pesquisa-ação crítico-colaborativa: construindo seu significado a partir de experiências com a formação docente. R evista E du cação e P esquisa, São Paulo, v. 31, n. 3, p. 521-39, 2005.

SILVA, S. C., ARANHA, M. S. F. Interação entre professora ealunos em salas de aula com proposta pedagógica de educação inclusiva. Revista Brasileira de E ducação Especial , Piracicaba, v.11, n. 3, p. 373-394, 2005.

VALENTE, P. et al. Atuação fonoaudiológica em creche de Belo Horizonte: relato de experiência. R evista C efac, São Paulo, v. 8, n.2, p. 240-3, 2006. 